\title{
Effect of prolonged cultivation on the micropropagation in vitro of mint cultivars and breeding samples
}

\author{
Margarita Zagorskaya*, and Natalia Yegorova \\ FSBSI "Research Institute of Agriculture of Crimea", Simferopol, 295493, Russia
}

\begin{abstract}
The influence of the genotype and the number of subcultures on the development of meristem cultures of five mint cultivars and breeding samples - Krasnodarskaya 2, Diana, K37, No. 2.8.14, $\mathrm{A}_{2}$ (Mentha spp.) was studied. At the second stage of micropropagation, the analysis of morphometric parameters of explants during six subcultures of four genotypes showed an increase in the multiplication index at $4-5^{\text {th }}$ passages, while in the sample $A_{2}$ - at $3-4^{\text {th }}$ passages.
\end{abstract}

\section{Introduction}

Mint is a well-known perennial herbaceous medicinal, essential oil and spicy aromatic plant in the family Lamiaceae. Different species of the genus Mentha are used in pharmacology, cosmetic and food industries, as well as in medicine. Preparations from mint plants have antiseptic, sedative, spasmolytic, and choleretic effect. Great interest to this valuable plant causes active development of breeding work, including creation of new essential oil cultivars. It is reasonable to involve biotechnological methods for the rapid propagation of the initial breeding material and cultivars, as well as for the development of techniques for their preservation in vitro.

The literature sources contain data regarding the studies related to the development of micropropagation methods for various mint species - Mentha piperita [1-3], M. viridis [4], M. canadensis, M. suaveolens, M. longiflora, M. aquatica, M. arvensis, M. $x$ gracilis, M. gracilis, M. spicata [5]. According to these sources, scientists used meristems, buds [1, $3,4]$ and stem segments with a node $[2,5]$ as explants in their experiments, as well as used different modifications of culture medium composition at the stages of propagation. However, many important issues of clonal micropropagation were not risen in these works, especially for cultivars and breeding samples of essential oil mint grown in the Crimea. The aim of our research was to study the influence of the genotype and the number of subcultures on the development of mint explants at the second stage of micropropagation in vitro.

\section{Materials and Methods}

\footnotetext{
* Corresponding author: zagorskayamargo@gmail.com
} 
Tissues and organs of mint cultivars and breeding samples - cultivar Diana (interline hybrid Mentha cadadensis L.), cultivar Krasnodarskaya 2 (obtained by selecting in the seed progeny of allopolyploid sample Mentha x piperita L.), sample K 37 (M. rotundifolia L. Huds), sample No. 2.8.14 (line $S_{1}$ of $M$. spicata $\mathrm{K} 65$ sample) and sample $\mathrm{A}_{2}$ (allopolyploid sample $M$. x piperita L.) [6] were used as the material for the study. Meristems with one pair of leaf primordia isolated from axillary buds were introduced in culture in vitro. At the $2^{\text {nd }}$ stage of micropropagation, segments of the stem with a node isolated from shoots, which were developed from meristems, were used as explants. Explants were cultivated on Murashige and Skoog culture medium (MS) supplemented with growth regulator such as BAP, Kinetin, IAA, GA 3 (Sigma, USA). Explants in test tubes were kept at $26^{\circ} \mathrm{C}, 70 \%$ of relative air humidity, under $16-\mathrm{h}$ photoperiod with illumination $2-3 \mathrm{klx}$.

Microcuttings were conducted every 40-45 days, before which the length and number of shoots, the number of nodes (pairs of leaves) on shoot, the frequency of rhizogenesis were determined. The multiplication index was calculated as the number of microcuttings that can be obtained during one subculture. For this the number of formed on the explant shoots was multiplied on the number of nodes on the shoot. Experiments on in vitro culture were carried out in three replications; at each variant 20 explants were analyzed. The data are processed using the Microsoft Office software package (Excel 2007). The tables show average values and their standard errors.

\section{Results and Discussion}

The studies revealed that active adventitious shoot formation and development of shoots which are long enough (up to $20-40 \mathrm{~mm}$ ) were observed for almost all genotypes (excluding $\mathrm{A}_{2}$ ) when introducing meristems in culture in vitro. For the further micropropagation at the $2^{\text {nd }}$ stage, microcutting of shoots was carried out. Microcuttings (segments of a stem with one node and a pair of leaves) were cultivated on the modification of MS culture medium with $1.0 \mathrm{mg} / 1 \mathrm{mg} \mathrm{L}^{-1} \mathrm{BAP}$ and $0.5 \mathrm{mg} \mathrm{L}^{-1} \mathrm{IAA}$, which we used for the propagation of other cultivars of peppermint [7]. It was identified that this medium was effective for four genotypes, whereas explants of sample $\mathrm{A}_{2}$ did not develop on it. Therefore, modification of MS medium with $0.5 \mathrm{mg} \mathrm{L}^{-1}$ Kinetin and $0.5 \mathrm{mg} \mathrm{L}^{-1} \mathrm{GA}_{3}$ was chosen for this sample in a separate experiment.

During microcuttings cultivation, on average developed 2.7-15.2 shoots per explant, depending on the number of subcultures and genotype (Table 1.). At the same time, active growth of axillary and adventitious shoots was observed. They reached a length of 15.2$49.7 \mathrm{~mm}$ after $40-45$ days of cultivation. Rhizogenesis with a frequency of 7.1 to $100 \%$ was observed for all studied genotypes at the second stage of propagation, during which an average of 1.0-5.7 roots per explants were formed. It was revealed that it is expedient to combine two methods for mint micropropagation in vitro - the induction of adventitious shoots and microcutting of main and additional shoots.

When analyzing the development of explants during six passages, the peculiarities of the influence of genotype and number of subcultures on the morphometric parameters of microshoots and multiplication index were identified (Table 1.). Gradual increase in the number and length of shoots and in the number of nodes during the $2-5^{\text {th }}$ passages was observed for cultivars Krasnodarskaya 2 and Diana. Rhizogenesis with a frequency of 95.0 to $100 \%$ was observed for these passages. The main parameter at the second stage of micropropagation - multiplication index was significantly increased; it reached a maximum (23.0-48.7) for these cultivars in $4-5^{\text {th }}$ passages. The decline of almost all the studied parameters occurred then in the $6^{\text {th }}$ passage. 
Table 1. Influence of subculture number and genotype on the development of mint explants on the second stage of micropropagation in vitro

\begin{tabular}{|c|c|c|c|c|c|c|}
\hline $\begin{array}{l}\text { Number of } \\
\text { subcultures }\end{array}$ & Cultivar, sample & $\begin{array}{l}\text { Shoots } \\
\text { number, } \\
\text { pcs. }\end{array}$ & $\begin{array}{l}\text { Shoots } \\
\text { length, } \\
\text { mm }\end{array}$ & $\begin{array}{c}\text { Nodes } \\
\text { number, } \\
\text { pcs. }\end{array}$ & $\begin{array}{c}\text { Rooting } \\
\text { frequency, } \\
\%\end{array}$ & $\begin{array}{l}\text { Multiplicat } \\
\text { ion index }\end{array}$ \\
\hline \multirow{5}{*}{1} & Krasnodarskaya 2 & $3.1 \pm 0.6$ & $15.2 \pm 1.2$ & $1.9 \pm 0.1$ & $7.1 \pm 0,7$ & $6.1 \pm 1,1$ \\
\hline & No. 2.8.14 & $5.9 \pm 0.6$ & $41.0 \pm 3.0$ & $2.9 \pm 0.2$ & $64.2 \pm 5,5$ & $17.6 \pm 2,7$ \\
\hline & Diana & $4.3 \pm 0.7$ & $33.0 \pm 2,2$ & $2.7 \pm 0.1$ & $31.2 \pm 2.2$ & $11.8 \pm 2.0$ \\
\hline & K 37 & $4.3 \pm 0.4$ & $39.9 \pm 3.3$ & $4.3 \pm 0.3$ & $93.7 \pm 8.8$ & $19.1 \pm 1.5$ \\
\hline & $\mathrm{A}_{2}$ & $3.4 \pm 1.3$ & $33.5 \pm 3.2$ & $3.1 \pm 0.2$ & $42.8 \pm 5.0$ & $10.7 \pm 1.9$ \\
\hline \multirow{5}{*}{2} & Krasnodarskaya 2 & $4.6 \pm 0.7$ & $27.1 \pm 2.1$ & $3.0 \pm 0.2$ & 100.0 & $14.2 \pm 2.3$ \\
\hline & No. 2.8 .14 & $4.0 \pm 0.3$ & $44.7 \pm 3.0$ & $3.6 \pm 0.2$ & $91.3 \pm 9.0$ & $14.9 \pm 1.0$ \\
\hline & Diana & $4.9 \pm 0.3$ & $44.9 \pm 2.7$ & $3.4 \pm 0.1$ & $95.8 \pm 8.9$ & $17.0 \pm 1.3$ \\
\hline & K 37 & $6.0 \pm 0.4$ & $26.7 \pm 1.8$ & $2.8 \pm 0.1$ & 100.0 & $17.1 \pm 1.1$ \\
\hline & $\mathrm{A}_{2}$ & $2.7 \pm 0.4$ & $41.5 \pm 4.8$ & $3.5 \pm 0.3$ & $90.0 \pm 8.8$ & $9.7 \pm 1.0$ \\
\hline \multirow{5}{*}{3} & Krasnodarskaya 2 & $12.3 \pm 1.0$ & $25.1 \pm 1.1$ & $2.2 \pm 0.1$ & $60.8 \pm 5.9$ & $27.7 \pm 2.7$ \\
\hline & No. 2.8.14 & $4.3 \pm 0.4$ & $33.7 \pm 3.1$ & $3.2 \pm 0.2$ & $91.3 \pm 8.9$ & $14.3 \pm 1.0$ \\
\hline & Diana & $5.3 \pm 0.5$ & $36.5 \pm 2.4$ & $3.3 \pm 0.1$ & 100.0 & $17.7 \pm 1.7$ \\
\hline & K 37 & $5.3 \pm 0.3$ & $38.3 \pm 2.5$ & $3.9 \pm 0.2$ & 100.0 & $21.3 \pm 1.9$ \\
\hline & $\mathrm{A}_{2}$ & $4.3 \pm 0.4$ & $39.1 \pm 3.6$ & $2.7 \pm 0.2$ & $90.0 \pm 8.7$ & $12.0 \pm 1.0$ \\
\hline \multirow{5}{*}{4} & Krasnodarskaya 2 & $15.2 \pm 0.7$ & $34.1 \pm 1.1$ & $3.2 \pm 0.1$ & 100.0 & $48.7 \pm 3.2$ \\
\hline & No. 2.8.14 & $3.6 \pm 0.6$ & $42.0 \pm 3.9$ & $3.7 \pm 0.3$ & $56.5 \pm 5.3$ & $13.8 \pm 1.4$ \\
\hline & Diana & $6.5 \pm 0.7$ & $38.9 \pm 2.3$ & $3.8 \pm 0.2$ & 100.0 & $24.7 \pm 2.1$ \\
\hline & K 37 & $5.3 \pm 0.3$ & $34.9 \pm 2.5$ & $3.7 \pm 0.2$ & 100.0 & $19.9 \pm 1.7$ \\
\hline & $\mathrm{A}_{2}$ & $3.4 \pm 0.3$ & $44.0 \pm 4.1$ & $3.5 \pm 0.3$ & $80.0 \pm 7.6$ & $12.1 \pm 2.0$ \\
\hline \multirow{5}{*}{5} & Krasnodarskaya 2 & $10.0 \pm 0.8$ & $49.7 \pm 2.1$ & $4.7 \pm 0.2$ & $95.2 \pm 8.5$ & $47.3 \pm 4.9$ \\
\hline & No. 2.8.14 & $4.8 \pm 0.6$ & $48.7 \pm 3.5$ & $4.1 \pm 0.2$ & $95.2 \pm 8.9$ & $20.1 \pm 2.7$ \\
\hline & Diana & $6.2 \pm 0.4$ & $46.0 \pm 2.6$ & $3.7 \pm 0.1$ & $95.2 \pm 8.9$ & $23.0 \pm 2.1$ \\
\hline & К 37 & $6.4 \pm 0.4$ & $40.1 \pm 2.2$ & $3.6 \pm 0.1$ & 100.0 & $23.3 \pm 2.2$ \\
\hline & $\mathrm{A}_{2}$ & $2.2 \pm 0.2$ & $41.7 \pm 4.4$ & $2.8 \pm 0.1$ & $60.0 \pm 5.4$ & $6.2 \pm 0.6$ \\
\hline \multirow{5}{*}{6} & Krasnodarskaya 2 & $4.5 \pm 0.7$ & $30.0 \pm 2.5$ & $2.4 \pm 0.1$ & $5.0 \pm 0.2$ & $10.9 \pm 1.6$ \\
\hline & No. 2.8 .14 & $3.8 \pm 0.4$ & $48.2 \pm 3.8$ & $3.6 \pm 0.2$ & $60.0 \pm 5.8$ & $14.0 \pm 1.5$ \\
\hline & Diana & $3.9 \pm 0.4$ & $42.1 \pm 3.1$ & $2.6 \pm 0.1$ & $45.0 \pm 3.9$ & $10.3 \pm 1.1$ \\
\hline & K 37 & $4.8 \pm 0.5$ & $39.4 \pm 3.1$ & $3.5 \pm 0.2$ & $65.0 \pm 6.6$ & $17.2 \pm 1.6$ \\
\hline & $\mathrm{A}_{2}$ & $2.1 \pm 0.2$ & $46.4 \pm 4.9$ & $3.9 \pm 0.4$ & $75.0 \pm 6.8$ & $8.4 \pm 1.1$ \\
\hline
\end{tabular}

Similar tendencies of development were observed in other mint genotypes, however, there were no significant differences in many parameters during the $2-5^{\text {th }}$ passages. However, the maximum multiplication index was identified for samples No. 2.8.14 (20.1) and K37 (23.3) in the fifth passage. After that, a slight decrease in the morphometric parameters was observed in the sixth passage. The maximum number of shoots, rooting frequency and multiplication index $(12.0-12.1)$ were noted in the $3-4^{\text {th }}$ subcultures for sample $\mathrm{A}_{2}$. Then, there was a significant decrease in parameters, and in the fifth passage the multiplication index was only 6.2 for this genotype.

Gomes et al. [5] when studying nine mint species during five passages also showed an increase in the multiplication index after the first passage. It reached the highest values in $3-5^{\text {th }}$ subcultures, depending on the species. The same situation of increasing the multiplication index to a certain passage during prolonged micropropagation was revealed for some other essential oil plants. Thus, at the $2^{\text {nd }}$ stage of micropropagation in vitro an increase in the multiplication index, which reached maximum in the third passage, was observed for the cultivars of essential oil rose [8] and lavender [9]. At the same time, this 
parameter for geranium was stable for two years, but for sage and fennel did not change significantly during the first three subcultures, and then it gradually decreased [9].

Comparing different mint genotypes, it was shown that 'Krasnodarskaya 2' had the best micropropagation ability. This cultivar showed the most active adventitious shoot formation, and as a result the number of shoots reached maximum value (15.2 per explant) in the $4^{\text {th }}$ passage. The largest average length of shoots and the number of nodes were in the $5^{\text {th }}$ passage. As a result, multiplication index for this cultivar reached the highest value 48.7. The parameters of explants development for sample $A_{2}$ were the lowest. Its multiplication index varied from 6.2 to 12.1 , depending on the passage.

Thus conducting mint propagation during six subcultures, it was established that the multiplication index was increased in the $4-5^{\text {th }}$ passages for cultivars Krasnodarskaya 2, Diana and samples K37 and No. 2.8.14. But for micropropagation sample $\mathrm{A}_{2}$ it was neccesary to use culture medium of another composition, on which this index reached a maximum in $3-4^{\text {th }}$ passages.

\section{References}

1. G.J. Minas, Acta Hort. 853, 77-82 (2010)

2. J. Mehta, R. Naruka, M. Sain, A. Dwivedi, D. Sharma, J. Mirza, Asian J. Plant Sci. Res. 2 , 518-523 (2012)

3. I.A. Bugara, Scientific Notes of Taurida V.I. Vernadsky National University, Ser. Biology, chemistry 26, 10-15 (2013)

4. H.D. Raja, D.I. Arockiasamy, Plant Tissue Cult. \& Biotech. 18, 1-6 (2008)

5. H.T. Gomes, P.M. Bartos, A.E. Marins, S.O.D. de Oliveira, J.E. Scherwinski-Pereira, Acta Scientiarum. Biol. Sci. 37, 405-410 (2015)

6. L.A. Bugaenko, N.P. Shilo, Polyploidy and interspecies hybridization in mint (Simferopol, Business-Inform, 2012)

7. M.S. Zagorskaya, N.A. Yegorova, Proceed. Int. Conf. dedicated to $85^{\text {th }}$ anniversary of the Central Bot. Gar. of the Nat. Academy of Sci. of Belarus 2, 205-208 (Medisont, Minsk, 2017)

8. N.A. Yegorova, I.V. Stavtzeva, Bull. of the State Nikit. Botan. Gard. 120, 36-43 (2016)

9. N.A. Yegorova, A.G. Krivokhatko, I.V. Stavtzeva, L.I. Kamenek, Taurida Herald of the Agrarian Sciences 1, 9-14 (2013) 